\title{
WORKABLE AND ROBUST CONCRETE USING HIGH VOLUME CONSTRUCTION AND DEMOLITION WASTE IN SUB TROPICAL CLIMATE
}

\author{
Nishant Yadav ${ }^{1 *}$, Dr. Shirish V. Deo ${ }^{2}$, Dr. G.D. Ramtekkar ${ }^{2}$ \\ ${ }^{1}$ Research Scholar, Department of Civil Engineering, National Institute of Technology, Raipur, \\ Chhattisgarh, India \\ ${ }^{2}$ Department of Civil Engineering, National Institute of Technology, Raipur, Chhattisgarh, India
}

(Received: December 2017 / Revised: February 2018 / Accepted: April 2018)

\begin{abstract}
Full fledged use of construction \& demolition (C\&D) waste in the construction industry is inevitable. Concrete technologists across the world are engaged to scale its properties and potential uses since last 65 years. The general consensus for the mechanical property is to some extent is acceptable however the workability and durability properties are still under a scanner and needs to be improved. The present paper reports the optimistic results of series of experimental work carried out using high range replacement of normal aggregates (NA) with recycled aggregates (RA) (50-80\%) from C\&D waste for producing sustainable and durable concrete (water cement ratio 0.4) using C\&D waste. Multiple strategies were used in research to enhance workability and durability properties of concrete produced by using C\&D waste. Firstly the RA was used as an internal curing (IC) agent to enhance the micro structure and Interfacial Transition Zone (ITZ) of concrete. Secondly by apparently lowering the water cement ratio by using additional low-lime fly ash similar to class F of ASTM C 618 mainly to improve workability, packing of concrete, later age strength and durability. The results show that water diffusion in concrete with RA being used as an IC agent was delayed leading to decrease in shrinkage and micro cracks development; also increase the hydration, compressive strength and improvement of durability indexes such carbonation depth and electrical resistivity is seen. The Scanning Electron Microscope (SEM) result illustrated the considerable improvement in the microstructure. By adopting these strategies which are economical \& sustainable, mixtures show additional benefits that should permit their broader application.
\end{abstract}

Keywords: Concrete; Construction \& Demolition (C\&D) waste; Interfacial Transition Zone (ITZ); Internal Curing (IC); Shrinkage

\section{INTRODUCTION}

Today land is a scarce commodity in the urban cities and to accommodate more population Floor Area Ratio is increased causing the demolition of existing structures for reconstruction. Good engineering practice advocates for recycling and reuse of materials. The reuse of Construction \& Demolition (C\&D) waste has potential to save a huge amount of natural resources, reduce $\mathrm{CO}_{2}$ footprint, reduce environmental impact, reduction of large space required for dumping sites, create space in urban areas, and also the creation of jobs and business opportunities (Yadav et al., 2017). The C\&D wastes mainly consist of concrete, brick, ceramic and mortar which together constitute around $80 \%$, but are in a complex mixed form and

*Corresponding author's email: nishant.yadav.bit@gmail.com, Tel: +919617080000

Permalink/DOI: https://doi.org/10.14716/ijtech.v9i3.1126 
requires processing before being put to use. Un-engineered disposal and illegal dumping of these C\&D waste is a threat and is causing environmental degradation. Huge heaps of C\&D waste causes rise in flood levels of the rivers, scouring of the banks, depletion of resources, leaching out of hazardous material in the water causing an impact on aquatic life. Buried wastes cause the formation of an impervious layer which does not allow the growth of vegetation and prevents infiltration of rainwater. The other environmental impact includes deforestation, illegal mining of river beds for aggregates, air and water pollution, consumption of fossil fuels for transportation, topsoil loss etc. (Yadav et al., 2017).

The general wisdom on the use of recycled aggregates for making concrete affects the workability, strength, and durability of concrete. To sum up the experimental investigations on concrete produced by using C\&D waste aggregate, $0-100 \%$ replacement of natural aggregates has already been done and reported. To scale the potential use of C\&D waste it is unreasonable to generalize all the results thus here the replacement is categorized into a low replacement (up to 50\%) and high replacement (more than 50\%). In low replacement, comparable compressive strength is achieved. At higher replacement percentage of natural aggregates with $\mathrm{C} \& \mathrm{D}$ waste aggregate, the compressive strength of concrete is reduced (Brito \& Saikia, 2013). The reason attributed to this is poor Interfacial Transition Zone (ITZ), (Medina et al., 2015). Concrete made with C\&D waste aggregates have poor workability and durability performance as compared to natural aggregates concrete (Bravo et al., 2015). For 100\% coarse recycled concrete aggregate (RCA) in concrete, Silva et al. (2015) reported an increase in shrinkage by up to $80 \%$. This high shrinkage characteristic causes micro cracks within the concrete matrix and leads to poor ITZ and durability issues in aggressive environments.

As per ACI-308, "Internal curing refers to the process by which the hydration of cement occurs because of the availability of additional internal water that is not part of the mixing water" (Bentz \& Weiss, 2011). Internal curing (IC) supplies the extra curing water throughout the concrete mix thus maintaining the relative humidity and avoiding selfdesiccation and reducing autogenous shrinkage. IC also works well with supplementary cementitious materials (SCM) like fly ash, especially at higher dosage levels, due to increased water demand for SCM reaction in later age. IC can address various ageold complex issues of concrete like shrinkage, prominent ITZ, a considerable fraction of unhydrated cement due to lack of proper curing, and durability issues arising from micro cracks due to various combinations of factors (Bentz \& Weiss, 2011). IC is an additional curing which supplements conventional curing. The effectiveness of an IC agent depends on the quantity of water IC agent can absorb and release in concrete. Brito and Saikia (2013) reported that recycled aggregates adheres mortar around 16-17\%, the water absorption capacity of recycled aggregate is also higher compared to natural aggregate. Recycled aggregates marginally qualifies as an IC agent and is not an effective IC agent because the pore size of the mortar or paste coating on its surface is smaller or of similar size as that of the mix around it. For proper functioning of IC mechanism pore size of the IC agent acting as a water reservoir should be larger than that of the mix around it. This is essential for the capillary pull of absorbed water from IC agent to the desiccating mix around (Bentz \& Weiss, 2011).

\subsection{Research Objective}

The primary objective of the research is to reuse the C\&D waste for producing concrete which is viable from laboratory research scale as well as for field practical implementation. To produce sustainable concrete using C\&D waste as an IC agent and hence to carry out a parametric study on the five essentials of modern concrete - Workability, Strength, Durability, Micro Structure, and Sustainability. The study also aims to address the 
contemporary issues of the modern concrete mentioned in conclusion and to propose simple and sustainable remedial measures to overcome limitations of using C\&D waste in concrete.

\section{MATERIAL AND METHODS}

\subsection{Material Specification}

In the present study ASTM C150 Type I - 43 Grade ordinary Portland cement (OPC) is used. Chemical composition is tabulated in Table 1 and basic test results are reported in Table 2.

Table 1 Cement chemical composition

\begin{tabular}{cccccccccccc}
\hline $\mathrm{SiO}_{2}$ & $\mathrm{Al}_{2} \mathrm{O}_{3}$ & $\mathrm{Fe}_{2} \mathrm{O}_{3}$ & $\mathrm{CaO}$ & $\mathrm{MgO}$ & $\mathrm{SO}_{3}$ & $\mathrm{Na}_{2} \mathrm{O}$ & $\mathrm{K}_{2} \mathrm{O}$ & $\mathrm{Cl}$ & $\begin{array}{c}\text { Ignition } \\
\text { loss }\end{array}$ & Ash & $\begin{array}{c}\text { Total Content } \\
\text { (wt } \%)\end{array}$ \\
\hline 20.9 & 3.50 & 4.38 & 64.6 & 1.20 & 3.07 & 0.22 & 0.38 & 0.082 & 1.27 & 0.2 & 99.97 \\
\hline
\end{tabular}

Table 2 Technical parameters of cement (as per various IS codes)

\begin{tabular}{ccccccc}
\hline $\begin{array}{c}\text { Sieve } \\
\text { fineness }\end{array}$ & $\begin{array}{c}\text { Consistency } \\
(\%)\end{array}$ & $\begin{array}{c}\text { Initial setting } \\
\text { time (min) }\end{array}$ & $\begin{array}{c}\text { Final setting } \\
\text { time }(\mathrm{min})\end{array}$ & $\begin{array}{c}\text { Soundness Le } \\
\text { Chatelier } \\
(\mathrm{mm})\end{array}$ & $\begin{array}{c}\text { Compressive } \\
\text { strength 28d } \\
(\mathrm{MPa})\end{array}$ & $\begin{array}{c}\text { Specific } \\
\text { Gravity }\end{array}$ \\
\hline $3.5 \%$ & 34 & 78 & 190 & 2 & 46.4 & 3.1 \\
\hline
\end{tabular}

Conplast SP430 super plasticizing admixture based on sulfonated naphthalene polymers is added in a fixed dosage of $1 \%$ ( $1 \mathrm{~g}$ per $100 \mathrm{~g}$ of cement) for desired workability at various replacements of natural aggregates with recycled aggregates in sub tropical climate.

The natural river sand of Zone-II as per IS 383-2013 with an apparent specific gravity of 2.62 is used. For coarse aggregate, $20 \mathrm{~mm}$ and $10 \mathrm{~mm}$ crushed aggregated are procured from local crusher. The Fly ash confirming to IS: 3812 (Part-1) and distilled water are used.

\subsection{Mix and Sample Production Process}

The w/c ratio, chemical admixture and sand are kept constant in the mix and three replacements are examined: $50 \%, 65 \%$, and $80 \%$. For replacement $10-20 \mathrm{~mm}$ size recycled aggregates are intentionally used as coarse aggregates the idea of using larger fractions is to reduce surface water demand. Intentional use of rounded natural aggregate of size 4.75-12.5 $\mathrm{mm}$ also helped in improving workability (Strategy 1). Based on the maximum density test conducted on the available material, the ratio of coarse aggregate fractions $20-16 \mathrm{~mm}$ and $16-10 \mathrm{~mm}$ in the mix is decided as $53 \%(16-20 \mathrm{~mm})$ and $47 \%(10-16 \mathrm{~mm})$ (Strategy 2). The properties of coarse and fine aggregates are in Table 3.

Table 3 Properties of aggregates

\begin{tabular}{lcccc}
\hline \multirow{2}{*}{ Properties } & \multicolumn{3}{c}{ Coarse aggregate } & Fine aggregate \\
\cline { 2 - 5 } & Normal Aggregate (NA) & $\begin{array}{c}\text { Recycled } \\
\text { Aggregate (RA) }\end{array}$ & \\
\cline { 2 - 5 } & $20-10 \mathrm{~mm}$ & $10-4.75 \mathrm{~mm}$ & $20-10 \mathrm{~mm}$ & 2.62 \\
\hline Specific gravity & 2.72 & 2.70 & 2.63 & 1.0 \\
\hline Water absorption (\%) & 0.5 & 0.58 & 4.6 & 1.61 \\
\hline Bulk density (Loose kg/litre) & 1.39 & 1.29 & - & 1.75 \\
\hline Bulk density (Rodded kg/litre) & 1.53 & 1.51 & - & 1.84 \\
\hline Bulk density(Vibrated Kg/litre) & 1.63 & 1.64 & - & 38.5 \\
\hline Percentage void (Loose) & 48 & 51 & - & 33.13 \\
\hline Percentage void (Rodded) & 43.5 & 44 & - & 29.77 \\
\hline Percentage void (Vibrated) & 39.9 & 40 & -- \\
\hline Crushing Value \% IS 2386 part IV & 13.85 & & 29.9 & -- \\
\hline Impact Value \% & 8.86 & & 27.6 & - \\
\hline
\end{tabular}


In the study, recycled aggregate is used as an Internal Curing (IC) agent, the quantity of water in the mix is critical. The quantity of water, coarse aggregate and recycled aggregate used is as per the mix design. The water absorption of recycled aggregate used is also predetermined. The recycled aggregates is submerged in a known quantity of water equal to w/c ratio + absorption capacity of recycled aggregates in a closed container ensuring that there is no loss of water due to evaporation. For mixing, the coarse aggregates including presoaked recycled aggregates and sand as per mix proportions are allowed to homogenize. Subsequently, cement, fly ash and the remaining water with the admixture is added. The known quantity of water used for immersing recycled aggregates is deducted from the final count of water to be used in the mix. This will ensure a consistent quantity of water in the subsequent mixes. The mixing process is more or less the same. (Yadav et al., 2018)

Additional fly ash is used to improve workability, packing, later age strength and durability of concrete. The fineness of fly ash is a key factor in its pozzolanic effect; fine fly ash may act as pozzolanic but coarser fly ash is essentially a filler material in concrete. Fly ash in two size fractions are used 90 microns passing fly ash is intended for pozzolanic action (Strategy 4) while 90-150 micron fraction as a filler material for better packing and durability(Strategy 5). A quantity of 90 micron fly ash is ascertained from calculation for apparently lowering the w/c ratio of mix using fly ash instead of additional cement (Table 4). Quantity of 90-150 micron fly ash is used as per the calculation of voids in mix. (Yadav et al., 2018)

\subsubsection{Quantity of fly ash used}

Quantity of fly ash in each mix is calculated by keeping cement content constant and stepping down the w/c ratio from 0.4 to 0.38 and 0.36 by adding micro fine fly ash as discussed above is tabulated in Table 4.

Table 4 Fly ash dosage for apparently lowering water cement ratio

\begin{tabular}{|c|c|c|c|c|c|}
\hline \multicolumn{3}{|c|}{ As Per Mix Design } & \multirow{4}{*}{$\begin{array}{c}\text { (Qty of water in mix/ Target } \\
\text { w/c ratio - Cement } \\
\text { Content)*100/ Cement } \\
\text { content }\end{array}$} & \multicolumn{2}{|c|}{ Target w/c ratio } \\
\hline \multirow{2}{*}{$\begin{array}{l}\mathrm{W} / \mathrm{C} \\
\text { ratio }\end{array}$} & \multirow{2}{*}{ Cement content } & \multirow{2}{*}{ Water } & & 0.36 & 0.38 \\
\hline & & & & \multicolumn{2}{|c|}{ Fly ash \% required } \\
\hline 0.4 & 400 & 160 & & 11.11 & 5.26 \\
\hline
\end{tabular}

\subsubsection{Quantity of recycled aggregate required for internal curing}

Bentz and Snyder (1999) used the Principle of supply and demand to estimate the volume of IC water needed and the dry mass of IC agent required is given in Equation 1, calculation of mass of dry recycled aggregate required is shown in Table 5.

$$
M R A=\frac{C f x C S x \propto \max }{S x \phi R A}
$$

where $\mathrm{M}_{\mathrm{RA}}$ is the mass of (dry) recycled aggregates per unit volume of concrete $\left(\mathrm{kg} / \mathrm{m}^{3}\right), \mathrm{Cf}$ is the cement content $\left(\mathrm{kg} / \mathrm{m}^{3}\right), \mathrm{CS}=0.7$ (Bentz \& Weiss, 2011) is the chemical shrinkage of cement ( $g$ of water/g of cement), $\alpha_{\max }$ is the maximum expected $\mathrm{DoH}$ of cement, $\mathrm{S}=1$ is the degree of saturation of aggregate ( 0 to 1$)$, and $\varphi_{R A}$ is the absorption of recycled aggregates $\mathrm{kg}$ water/kg dry recycled aggregates. Correct approach for the value of $\Phi$ is to use the measured desorption capacity of the IC agent at $92 \%$ relative humidity (Bentz et al., 2005). 
Table $5 \mathrm{M}_{\mathrm{RA}}$, Mass of dry recycled aggregates (RA) required

\begin{tabular}{|c|c|c|}
\hline \multirow{2}{*}{$\begin{array}{l}\text { Degree of } \\
\text { Hydration }\end{array}$} & \multicolumn{2}{|c|}{$\begin{array}{c}\varphi_{\mathrm{RA}}, \text { Absorption of } \mathrm{RA}=4.6 \%, \\
\text { Qty of natural aggregates (NA) in mix (as per mix design) }=1196.8 \mathrm{~kg} / \mathrm{m}^{3}\end{array}$} \\
\hline & \multicolumn{2}{|c|}{$\mathrm{w} / \mathrm{c}$ ratio $=0.4, \mathrm{CS}=0.7, \mathrm{Cf}=$ cement content in $\operatorname{mix}=400 \mathrm{~kg} / \mathrm{m}^{3}$} \\
\hline$\overline{\alpha_{\max }}$ & MLWA, Mass of dry RA required $\mathrm{kg} / \mathrm{m}^{3}$ & \%age replacement of NA \\
\hline 0.2 & 121.739 & 10.17 \\
\hline 0.4 & 243.478 & 20.34 \\
\hline 0.5 & 304.348 & 25.43 \\
\hline 0.6 & 365.217 & 30.52 \\
\hline 0.8 & 486.957 & 40.69 \\
\hline 1 & 608.696 & 50.86 \\
\hline
\end{tabular}

Only $50.86 \%$ replacement of natural aggregate with recycled aggregate as IC agent is sufficient for full hydration as per Table 6 using Equation 1. In case of higher replacements, i.e. $65 \%$ and $80 \%$ suitable adjustment of surplus water are made by reducing the quantity of mixing water by an equal amount of absorbed water in presoaked recycled aggregate beyond $50.86 \%$. All ingredients are stored in room temperature. 160 cubes of size $100 \times 100 \times 100 \mathrm{~mm}^{3}$ are casted for all mixes and tested for determining compressive strength at various curing days (7,28, 56 and 119days) and compare the trend of strength development with control mix likewise 90 beams of size $500 \times 100 \times 100 \mathrm{~mm}^{3}$ are also casted and tested for flexural strength. Moulds coated with an anti-adhesive substance are filled and compacted. The samples are demoulded after $24 \mathrm{~h}$, and then suitably cured. Since fly ash is used proper and longer curing is ensured for favorable results.

\subsection{Test Methods}

\subsubsection{Fresh concrete properties}

Experimental study carried out on fresh concrete are: slump cone, compaction factor, rheology, shrinkage and electrical resistivity. Schleibinger rheometer EBT-2 is used to study rheology, shrinkage is measured using the Schleibinger Shrinkage Cone deltaEL, Electricity Resistance Giatec RCON2 ${ }^{\mathrm{TM}}$ two-probe (electrode) is used to determine the Concrete Bulk Resistivity.

\subsubsection{Compressive strength}

7, 28, 56 and 119 days compressive strength is determined as per ASTM C39/C39M using $100 \mathrm{~mm}$ concrete cubes specimen, the rate of loading applied is $140 \mathrm{~kg} / \mathrm{cm}^{2}$ per minute till the specimen fails. The compressive strength of concrete is the failure load divided by the cross sectional area.

\subsubsection{Flexural strength}

The 28 days and 56 days flexural strength test is performed as per ASTM C78/C78M-16 using simple beam with third-point loading, Spacing of the supports is $300 \mathrm{~mm}$.

\subsubsection{Electrical Resistivity}

Bulk Electrical Resistivity Test (ER) is carried as per ASTMC1202. The fully saturated cubes are placed in between two parallel metal plates within moist sponge of ER meter. The voltage between two ends of the specimen is measured by applying small alternating current at intended frequency. The impedance $\mathrm{Z}$ is displayed on the monitor of ER meter. Concrete resistivity is then determined using Equation 2: 


$$
\rho=\frac{A \times Z}{L}
$$

where, $\rho$ is the resistivity of concrete $(\Omega \mathrm{cm})$, A is the cross sectional area of the specimen $\left(\mathrm{cm}^{2}\right), \mathrm{L}$ is the length of specimen $(\mathrm{cm})$ and $\mathrm{Z}$ denotes impedance measured by ER meter $(\Omega)$.

\subsubsection{Microstructure investigations}

To examine the effects of IC using recycled aggregate as an IC agent and to ascertain the transport and durability properties of this sustainable modified concrete micro structure investigation is justified. For the investigation Zeiss make Scanning Electron Microscope (SEM) equipped with a chemical compounds analysis system based on Energy Dispersive Spectrometry (EDS) is used. SEM observations are examined on 119 days samples. Small specimens of size around 4-5 $\mathrm{mm}$ are extracted from fractured concrete cubes, the surface of the specimen is polished and mounted on gold splutter coater for gold coating and mounted on aluminum stub for scanning the image at high resolution. The SEM images of different mixes are taken at various magnifications as per the requirements of our study.

\subsubsection{Carbonation}

Three air dried 56 days cured cube specimens of each mix are placed in carbonation chamber such that the circulation of air in not restricted. The chamber is set at a constant temperature of $33^{\circ} \mathrm{C}$ and humidity $70 \%$, and the rate of carbonation is set to $5 \%$. The reason for selecting higher temperature is to simulate sub tropical climate. An accelerated carbonation is carried out for 60 days and the phenolphthalein test is used to measure carbonation depth. Phenolphthalein solution as required is procured from local market. The cubes are fractured using compression testing machine and the inner surface is cleaned of dust and loose particles. The Phenolphthalein solution is sprayed over the fractured concrete surface. Phenolphthalein is a colorless acid indicator which turns pink when the concrete is alkaline, that is when the $\mathrm{pH}$ more than 9.5. No change in color indicates that carbonation has taken place and the carbonation depth can be measured from the surface. Herrera et al. (2015).

\subsubsection{Degree of hydration}

Estimating the Degree of Hydration $(\mathrm{DoH})$ of cement in concrete with recycled aggregate is complicated. The pieces of 28 days fractured cubes are soaked in acetone to stop the hydration reactions. On the day before the test the acetone is removed and the samples are dried at $60^{\circ} \mathrm{C}$ in an oven for $24 \mathrm{~h}$ and are ground to pass through 150 micron sieve. To determine the non-evaporable water, Lam et al. (2000) was followed, the LOI was calculated then Wn and then DoH is calculated. To determine LOI $5 \mathrm{~g}$ of grounded sample passing through 150 micron sieve is ignited at $950^{\circ} \mathrm{C}$ in an electric furnace for $1 \mathrm{~h}$. The loss on ignition (LOI) of the hydrated cement pastes is calculated by Equation 3:

$$
\text { LOI }(\%)=100 \times(\text { wt of sample-ignited weight }) / \text { ignited weight }
$$

The content of hydrated pastes, Wn is determined by oven drying $5 \mathrm{~g}$ of the powdered hydrated sample at $110^{\circ} \mathrm{C}$ for $3 \mathrm{~h}$ in an oven, and then ignited at $950^{\circ} \mathrm{C}$ in an electric furnace for $1 \mathrm{~h}$. The $\mathrm{Wn}$ is calculated by using Equation 4:

$$
\mathrm{Wn}(\%)=100 \times[(\text { wt. of dried sample-ignited wt. of sample)/(ignited wt. of sample)-LOI] }
$$

The hydration of $1 \mathrm{~g}$ of anhydrous cement produces $0.23 \mathrm{~g}$ of Wn. (Neville, 2009).

The DoH $(\%)$ of the cement in the sample is $=100 \times \mathrm{Wn} / 0.23$ 


\section{RESULTS AND DISCUSSION}

\subsection{Fresh Concrete Properties}

Surface texture of aggregate controls the workability of concrete. Recycled aggregates have an uneven coat of mortar and paste around which offers infinite surface area due to which the demand for surface water increases and interlocking of particle also affects workability. It is justified to comment that results of slump cone test alone are not dependable when recycled aggregates in high quantity are used for making concrete. Compaction factor and Rheology tests give more reliable results and are suitable for assessing the effects of various replacements and dosages of ingredients in subsequent batches on trial mix.

Slump value decreased drastically when natural aggregates are replaced by higher percentage of recycled aggregates $(50 \%, 65 \%$, and $80 \%)$. However some improvement in slump value is seen when fly ash $5.26 \%$ is used. At higher dosage of fly ash $11.11 \%$ this advantage is slightly lost due to lack of availability of free water in mix it is because higher requirement of surface water for fly ash. All the three tests confirm that the various strategy applied in the experimental study to enhance the workability has worked out. A decent workable mix is obtained with $50 \%$ and $65 \%$ natural aggregates replaced with recycled aggregate having $5.26 \%$ fly ash and size fraction adjustments of coarse aggregate as discussed earlier.

\subsection{Fresh Concrete Properties-Shrinkage}

Shrinkage is volumetric change associated with movement of water in the paste phase, decrease in shrinkage in the course of study is evidence that IC mechanism worked in concrete with recycled aggregate as an IC agent. The water diffusion is delayed in concrete leading to decrease in shrinkage and micro cracks development. Additional fly ash in the mix is also an explanation for decrease in shrinkage along with IC action. IC and proper gradation of coarse aggregates, fine aggregate and fly ash (strategy 1 to 5) reduced shrinkage by 20-25\% compare Mix 1 with Mix 2, 3 and 4 . The use of fly ash as a filler material along with IC mechanism and proper gradations of aggregates and fly ash reduce shrinkage by more than $50 \%$ as compared to control mix

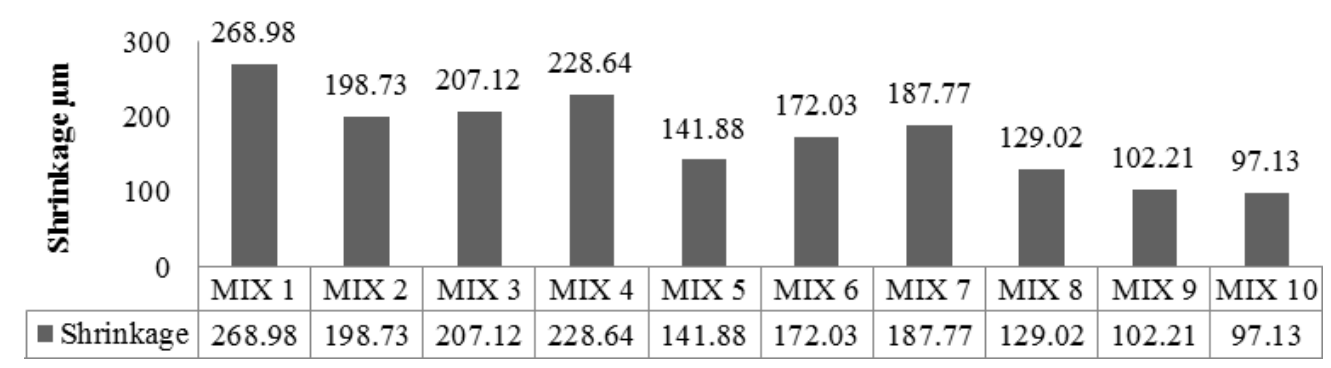

Figure 1 Variation in properties of fresh concrete - shrinkage $(\mu \mathrm{m})$

Table 6 Summary of results - fresh concrete properties

\begin{tabular}{|c|c|c|c|c|c|}
\hline & \multirow{2}{*}{ Mix } & \multirow{2}{*}{$\begin{array}{c}\text { Slump } \\
\mathrm{mm}\end{array}$} & \multirow{2}{*}{$\begin{array}{c}\text { Compaction } \\
\text { Factor }\end{array}$} & \multirow{2}{*}{$\begin{array}{c}\text { Rheology } \\
\text { Yield } \\
\text { Stress }\end{array}$} & \multirow{2}{*}{$\begin{array}{r}\text { Electrical } \\
\text { resistivity } \\
\Omega\end{array}$} \\
\hline & & & & & \\
\hline MIX 1 & Control Mix & 80 & 0.94 & 442.6 & 44.6 \\
\hline MIX 2 & $\begin{array}{l}50 \% \text { replacement of natural aggregate } \\
\text { (NA) with pre-soaked recycled } \\
\text { aggregate (RA) }\end{array}$ & 25 & 0.85 & 671.2 & 38.9 \\
\hline MIX 3 & $\begin{array}{l}65 \% \text { replacement of NA with pre-soaked } \\
\text { RA }\end{array}$ & 25 & 0.84 & 791.6 & 36.1 \\
\hline
\end{tabular}


in Sub Tropical Climate

\begin{tabular}{|c|c|c|c|c|c|}
\hline MIX 4 & $\begin{array}{l}80 \% \text { replacement of NA with pre-soaked } \\
\text { RA }\end{array}$ & 10 & 0.82 & 832.4 & 35.2 \\
\hline MIX 5 & $\begin{array}{l}5.26 \% \text { additional FA by weight of } \\
\text { cement }+50 \% \text { replacement of NA with } \\
\text { RA }\end{array}$ & 45 & 0.91 & 479.8 & 45.1 \\
\hline MIX $6^{-\cdots \cdots}$ & $\begin{array}{l}5.26 \% \text { additional FA by weight of } \\
\text { cement }+65 \% \text { replacement of NA with } \\
\text { RA }\end{array}$ & 45 & 0.88 & 504 & 39.1 \\
\hline MIX 7 & $\begin{array}{l}5.26 \% \text { additional FA by weight of } \\
\text { cement }+80 \% \text { replacement of NA with } \\
\text { RA }\end{array}$ & 35 & 0.88 & 655.6 & 37.6 \\
\hline MIX 8 & $\begin{array}{l}11.11 \% \text { additional FA by weight of } \\
\text { cement }+50 \% \text { replacement of NA with } \\
\text { RA }\end{array}$ & 35 & 0.90 & 554 & 48.3 \\
\hline MIX 9 & $\begin{array}{l}11.11 \% \text { additional FA by weight of } \\
\text { cement }+65 \% \text { replacement of NA with } \\
\text { RA }\end{array}$ & 30 & 0.89 & 670.4 & 49.1 \\
\hline MIX 10 & $\begin{array}{l}11.11 \% \text { additional FA by weight of } \\
\text { cement }+80 \% \text { replacement of NA with } \\
\text { RA }\end{array}$ & 25 & 0.87 & 686.8 & 53.9 \\
\hline
\end{tabular}

3.3. Mechanical Properties of Concrete-Compressive Strength and Flexural Strength Compressive strength related issue with use of recycled aggregate is successfully addressed in the study. The loss in compressive strength was of a magnitude of $7 \%$ to $19 \%$ with an increase in the replacement dosage of natural aggregate with recycled aggregates, and it was more noticeable at early age in all cases, which was mainly attributed to prominent ITZ and poor micro structure. With the addition of fly ash, the strength was comparable to the control mix in all cases at a later age (28 days) with proper curing.

Increase in strength is compared with corresponding lowest result following aggregate replacements, in case of $50 \%$ natural aggregate replacement with recycled aggregate increase in 28 days strength of $18.56 \%$ is seen with $5.26 \%$ fly ash and $21.85 \%$ with fly ash dosage of $11.11 \%$. For $65 \%$ natural aggregate replaced with recycled aggregate increase in 28 days strength of $21.5 \%$ is seen with $5.26 \%$ fly ash and $25.1 \%$ with fly ash dosage of $11.11 \%$. Increase in $28 \mathrm{~d}$ compressive strength for concrete with $80 \%$ natural aggregate replaced with recycled aggregate is $26.1 \%$ is seen with $5.26 \%$ fly ash and $29.8 \%$ with fly ash dosage of $11.11 \%$. However, the flexural strength of concrete could not reach the expected value during the study. In all cases, the flexural strength is less than the control mix. The increase in strength is due to multi fold strategies used like proper gradation of coarse aggregates along with fly ash in two different sizes to offer better packing to the mix. Internal curing also contributes in improving micro structure by restricting shrinkage. The flexural strength can be improved by using suitable fiber. However addition of fiber in the mix will further decrease workability. Results are tabulated in Table 7.

Table 7 Summary of results-mechanical properties of concrete

\begin{tabular}{|c|c|c|c|c|c|c|c|}
\hline & \multirow[t]{2}{*}{ Mix } & \multicolumn{4}{|c|}{$\begin{array}{l}\text { Average Compressive Strength } \\
\qquad \mathrm{N} / \mathrm{mm}^{2}\end{array}$} & \multicolumn{2}{|c|}{$\begin{array}{c}\text { Average Flexural } \\
\text { strength } \mathrm{N} / \mathrm{mm}^{2}\end{array}$} \\
\hline & & 7 days & 28 days & 56 days & 119 days & 28 days & 56 days \\
\hline MIX 1 & Control Mix & 20.4 & 36 & 40.6 & 45.5 & 4.2 & 5.6 \\
\hline MIX 2 & $\begin{array}{l}50 \% \text { replacement of NA with } \\
\text { pre-soaked RA }\end{array}$ & 18.5 & 33.4 & 39.1 & 42.3 & 3.1 & 3.8 \\
\hline MIX 3 & $\begin{array}{l}65 \% \text { replacement of NA with } \\
\text { pre-soaked RA }\end{array}$ & 17.2 & 30.6 & 33.3 & 35.5 & 2.84 & 3.4 \\
\hline MIX 4 & $\begin{array}{l}80 \% \text { replacement of NA with } \\
\text { presoaked RA }\end{array}$ & 17 & 29.1 & 32 & 34.6 & 2.48 & 3.3 \\
\hline
\end{tabular}




\begin{tabular}{|c|c|c|c|c|c|c|c|}
\hline MIX 5 & $\begin{array}{l}5.26 \% \text { additional FA by weight } \\
\text { of cement }+50 \% \text { replacement of } \\
\text { NA with RA }\end{array}$ & 17.8 & 39.6 & 45.5 & 49.6 & 3.4 & 4.1 \\
\hline MIX 6 & $\begin{array}{l}5.26 \% \text { additional FA by weight } \\
\text { of cement }+65 \% \text { replacement of } \\
\text { NA with RA }\end{array}$ & 16.5 & 37.2 & 42.4 & 45.5 & 3.1 & 4 \\
\hline MIX 7 & $\begin{array}{l}5.26 \% \text { additional FA by weight } \\
\text { of cement }+80 \% \text { replacement of } \\
\text { NA with RA }\end{array}$ & 18.7 & 36.7 & 43.5 & 47.2 & 3 & 3.86 \\
\hline MIX 8 & $\begin{array}{l}11.11 \% \text { additional FA by weight } \\
\text { of cement }+50 \% \text { replacement of } \\
\text { NA with RA }\end{array}$ & 15.1 & 40.7 & 48.9 & 52.8 & 3.8 & 4.8 \\
\hline MIX 9 & $\begin{array}{l}11.11 \% \text { additional FA by weight } \\
\text { of cement }+65 \% \text { replacement of } \\
\text { NA with RA }\end{array}$ & 17.3 & 38.3 & 43.9 & 47.5 & 3.4 & 4.4 \\
\hline MIX 10 & $\begin{array}{l}11.11 \% \text { additional FA by weight } \\
\text { of cement }+80 \% \text { replacement of } \\
\text { NA with RA }\end{array}$ & 17.8 & 37.8 & 44.1 & 48 & 3.3 & 4.6 \\
\hline
\end{tabular}

\subsection{Durability of Concrete Properties-Carbonation, SEM and Degree of Hydration}

In the Mix 2, 3 and 4 the carbonation depth is seen to increase compared to Mix 1 which indicates poor durability of concrete (Figure 2). When additional fly ash was added (5.26\% and $11.11 \%$ ) to the mix due to internal curing and better packing of the ingredients in the mix as micro-aggregates, the depth of carbonation reduced substantially in mixes 5 to 10 .

\subsection{Degree of Hydration (DoH)}

The average results of the 12 samples for each mix, made from 3 different cubes up to one decimal point are presented in Figure 3. The degree of cement hydration is calculated by determining the non-evaporable water content. The average DoH for control mix is $55.4 \%$ and that of concrete with recycled aggregate is $60.76 \%$ with increase in replacement of natural aggregate with recycled aggregate $(50 \%, 65 \%$ and $80 \%)$ the DoH increases by $7.2 \%$, $9.75 \%$ and $12.09 \%$, respectively.

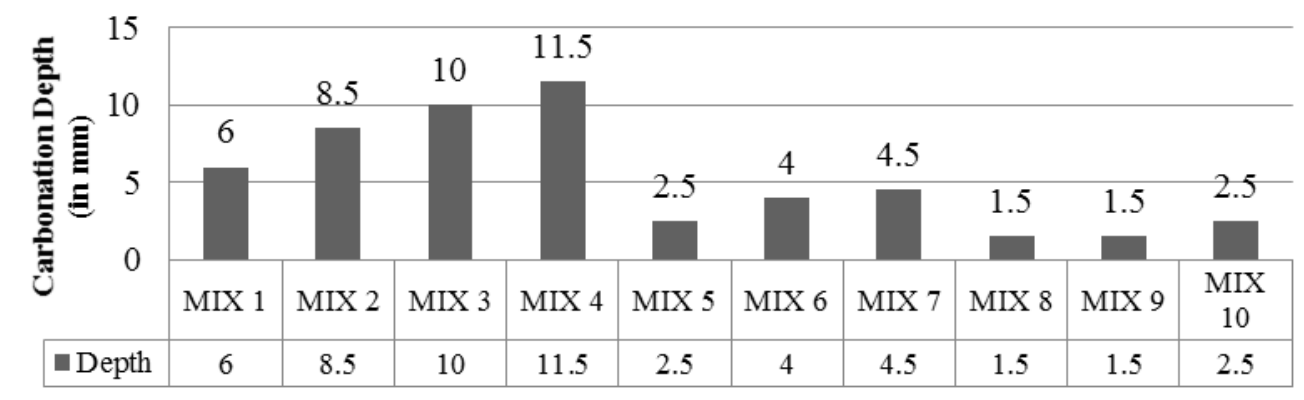

Figure 2 Variation in properties of hardened concrete-depth of carbonation

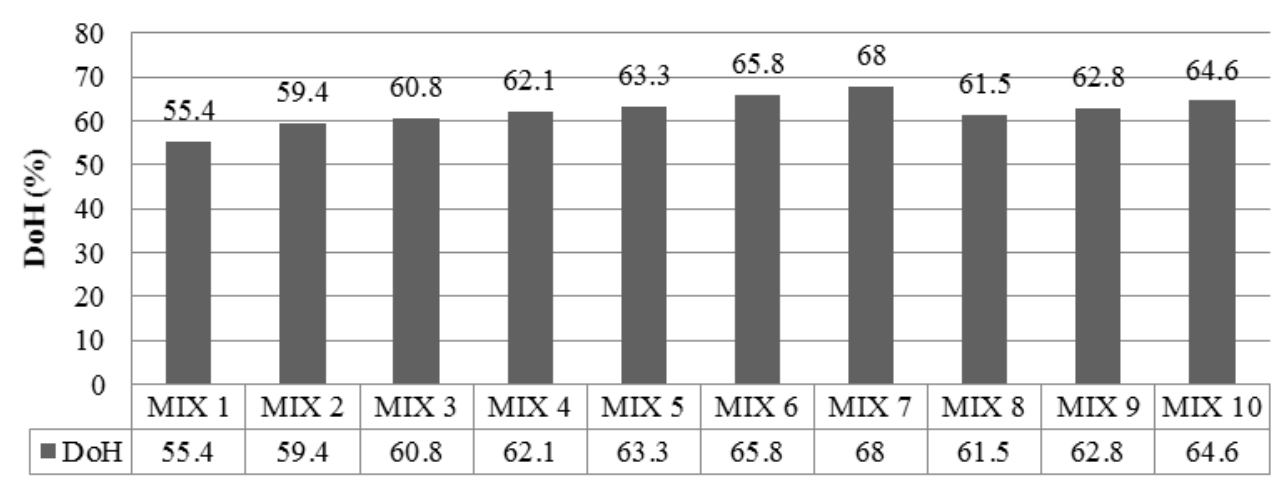

Figure 3 Variation in properties of hardened concrete-degree of hydration 
The higher DoH can be attributed to IC and external curing through porous and permeable concrete made by using recycled aggregate. An average increase of $18.5 \%$ in $\mathrm{DoH}$ in concrete with $5.26 \% \mathrm{FA}$ is observed this can be attributed to the contribution of fly ash reaction and IC. Whereas only $13.65 \%$ increase in DoH with $11.11 \%$ fly ash is observed. When higher dosage of fly ash is used the packing of the mix is improved due to the presence of micro aggregates in the mix. However, the amount of water bound in fly ash Pozzolanic reaction is uncertain. The Pozzolanic fly ash reaction consumes $\mathrm{Ca}(\mathrm{OH})_{2}$, which is used for assessing the DoH. Thus, the exact estimation of what fractions of additional fly ash (pozzolanic hydration) or cement (hydraulic hydration) is hydrated is not quantified in the present study.

\subsection{Micro Structure using SEM}

For the study, Ramachandran and James (2001) and Mehta and Monteiro (2009) are referred. The platy crystals are calcium hydrates with a distinctive hexagonal prism. More platy crystals structures are seen in control concrete (Mix 1). When fly ash is used calcium hydrates reacts with silica present in FA and formed CSH gel and ettringite. This is validated in Mix 5 and 8 the amount of calcium hydrate crystal is lesser as compared to control concrete.

The scanned images also show that the voids present in the controlled concrete (i.e. Mix -1 ) are more and the amount of CSH gels and ettringite needles are less than other mixes. The needle like structure in SEM, ettringite and fibrous structure the CSH gel are seen in considerable more amounts in Mix 5 and 8. This also validates higher $\mathrm{DoH}$ and functioning of IC mechanism in the mix. The higher amount of ettringite and CSH gels in SEM image in concrete with additional fly ash in the mix indicates that pozzolanic reaction of fly ash has taken place due to extended curing and IC mechanism. Over all dense micro structure is seen in SEM images of mix 5 to 10 having additional fly ash in the mix which indicates compact, durable concrete with greater service life. However the result could not be quantified.

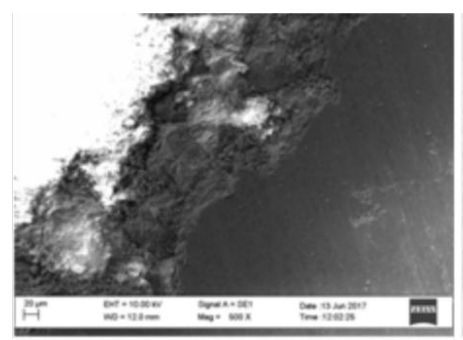

Figure 4:Prominent visible ITZ

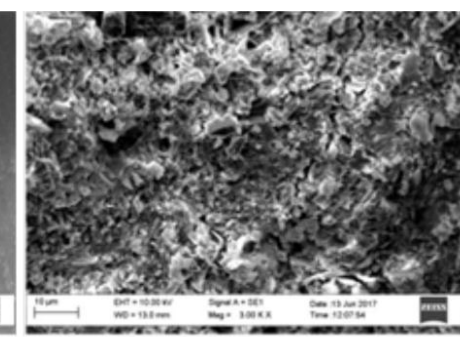

Hydrated products

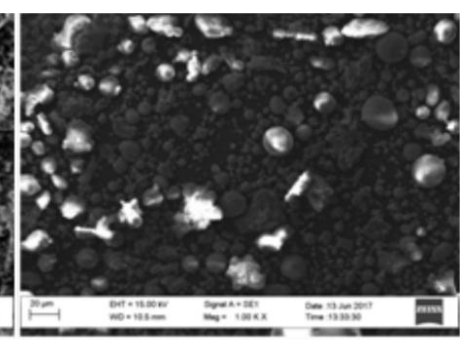

Unhydrated Fly ash as micro aggregates

Figure 4 Micro structure investigation of hardened concrete-SEM images

The SEM images confirms that the use of the said multiple strategies have brought improvement in ITZ of concrete, caused better cement hydration producing desirable hydrated products due to IC. Dense compacted micro structure also indicates that shrinkage has been restrained successfully. Proper curing reduces the stress and cracking potential due to temperature change and drying. Due to presence of IC water concrete behaves as a viscoelastic material which is beneficial for concrete as the stress is released. All cracks cannot be removed through IC; only cracks due to thermal stress and shrinkage can be controlled. Chemical shrinkage is inevitable as stated by Le Chatelier (Neville, 2009). A good micro structure of the hardened concrete indicates dense concrete with reduced porosity and lesser permeability which are important index for durability and performance of concrete. This increases service life, decreases maintenance cost and retards chemical ingress in concrete. 
The present study has successfully addressed the contemporary issues of modern concrete using C\&D waste recycled aggregate and by applying simple sustainable strategies which are listed in Table 8. Using multiple strategies improvement in the parameters of interest has been seen and reported in the paper the summary of result is tabulated in Table 9.

Table 8 Check list for contemporary issues addressed through the study

\begin{tabular}{lc}
\hline How to reduce the quantity of cement in concrete? & $\times$ \\
How to reduce the use of natural aggregate whose resources are limited? & $\sqrt{ }$ \\
\hline How to increase the effectiveness of curing? & $\sqrt{ }$ \\
How to improve Interface Transition Zone (ITZ)? & $\sqrt{ }$ \\
\hline How to reduce early age shrinkage? & $\times$ \\
\hline Maximize the utilization of C\&D waste in construction. & $\times$ \\
\hline Finding methods to reduce the use of potable water in construction work. \\
\hline
\end{tabular}

Notes; $\sqrt{ }:$ Partially addressed, $\sqrt{ } \sqrt{ }:$ Strongly addressed, $\times$ : not addressed

Table 9 Qualitative summary of results of the study using multiple strategies

\begin{tabular}{lccccc}
\hline Parameters & $\begin{array}{c}\text { Strategy 1 } \\
\text { Adjusting size } \\
\text { fraction of CA }\end{array}$ & $\begin{array}{c}\text { Strategy 2 } \\
\text { Adjusting CA } \\
\text { to CA ratio }\end{array}$ & $\begin{array}{c}\text { Strategy 3 } \\
\text { Application as } \\
\text { IC agent }\end{array}$ & $\begin{array}{c}\text { Strategy 4 } \\
\text { Lowering } \\
\text { w/c ratio }\end{array}$ & $\begin{array}{c}\text { Strategy 5 } \\
\text { Minimize } \\
\text { voids }\end{array}$ \\
\hline Workability & $\sqrt{ }$ & $\sqrt{ }$ & $\sqrt{ }$ & $\times$ & $\times$ \\
\hline Strength & $\sqrt{ }$ & $\sqrt{ }$ & $\sqrt{\sqrt{ }}$ & $\sqrt{\sqrt{ }}$ \\
\hline Durability & $\sqrt{ }$ & $\sqrt{ }$ & $\sqrt{ }$ & $\sqrt{\sqrt{ }}$ \\
\hline Micro Structure & $\sqrt{ }$ & $-\sqrt{\sqrt{ }}$ & - & $\sqrt{\sqrt{ }}$ \\
\hline Sustainability & - & - & - & \\
\hline
\end{tabular}

Notes; $\sqrt{ }$ : improvement, $\sqrt{ } \sqrt{ }:$ significant improvement,$\times:$ no improvement, $-:$ no effect

\section{CONCLUSION}

The constraints of using C\&D waste as coarse aggregate for making concrete: workability and durability issues have been successfully dealt with by using multiple strategies. Higher DoH should result in higher shrinkage, but in the present study, using multiple strategies the shrinkage in the mix has been restricted successfully in spite of the increase in DoH. Adjusting proportions of coarse aggregate fractions using maximum density method and minimizing voids by using additional fly ash is highly recommended for better strength and durability of concrete. Internal curing should be applied for field applications especially in sub tropical regions it is the grey area of study and scope for future work are as follows: (1) The benefits of using combinations of different size fractions of coarse aggregates, recycled aggregates and fly ash are clearly seen in results of strength and durability. However the evidence that which size fraction of fly ash precisely contributed to which property of concrete in the present study could not be mapped. This calls for a further specific study in some advanced research laboratory; (2) Smaller fractions of coarse aggregate $(4.75 \mathrm{~mm}-10$ $\mathrm{mm}$ ) can be used which might give some interesting results, as smaller recycled aggregates as an IC agent will have better distribution across the mix. Three replacements $(50 \%, 65 \%$ and $80 \%$ ) using recycled aggregates are tried in the present study however it is expected that even better results exist between $50 \%$ and $65 \%$ replacements. Further, it is suggested to carry out a similar test using micro step increment of fly ash dose between $5.26 \%$ and $11.11 \%$. 


\section{REFERENCES}

Bentz, D.P., Weiss, W.J., 2011. Internal Curing: A 2010 State-of-the-Art Review, National Institute of Standards and Technology, NISTIR 7765, U.S. Dept of Commerce

Bentz, D.P., Lura, P., Roberts, J.W., 2005. Mixture Proportioning for Internal Curing. Concrete International, Volume 27(2), pp. 35-40

Bentz, D.P., Snyder, K.A., 1999. Protected Paste Volume in Concrete: Extension to Internal Curing using Saturated Lightweight Fine Aggregate. Cement and Concrete Research, Volume 29(11), pp. 1863-1867

Bravo, M., Brito, J., Pontes, J., Evangelista, L., 2015. Durability Performance of Concrete with Recycled Aggregates from Construction and Demolition Waste Plants. Construction and Building Materials, Volume 77, pp. 357-369

Brito, J., Saikia, N., 2013. Recycled Concrete in Aggregate. Springer-Verlag London

Herrera-Durán, A., Mendoza-Rangel, J.M., De-Los-Santos, E.U., Vázquez, F., Valdez, P., Bentz, D.P., 2015. Accelerated and Natural Carbonation of Concretes with Internal Curing and Shrinkage/ Viscosity Modifiers. Materials and Structures, Volume 48(4), pp. 1207-1214

Lam, L., Wong, Y.L., Poon, C.S., 2000. Degree of Hydration and Gel/Space Ratio of Highvolume Fly Ash/Cement Systems. Cement and Concrete Research, Volume 30(5), pp. $747-756$

Medina, C., Zhu, W., Howind, T., Frías, M., Sánchez de Rojas, M.I., 2015. Effect of the Constituents (Asphalt, Clay Materials, Floating Particles and Fines) of Construction and Demolition Waste on the Properties of Recycled Concretes. Construction and Building Materials, Volume 79, pp. 22-33

Mehta, P.K., Monteiro, P.J.M., 2009. Concrete - Microstructure, Properties and Materials. Third Edition, Tata McGraw Hill

Neville, A.M., 2009. Properties of Concrete. Fourth Impression, Pearson Education

Ramachandran, V., Beaudoin, J.J., 2001. Handbook of Analytical Techniques in Concrete. William Andrew Publishing/Noyes Publications

Silva, R.V., De Brito, J., Dhir, R.K., 2015. Prediction of the Shrinkage Behaviour of Recycled Aggregate Concrete: A Review. Construction and Building Materials Volume 77, pp. 327-339

Yadav, N., Deo, S.V., Ramtekkar, G.D., 2017. Mechanism and Benefits of Internal Curing of Concrete using Light Weight Aggregates and its Future Prospects in Indian Construction Industry. International Journal of Civil Engineering \& Technology, Volume 8(5), pp. 323-334

Yadav, N., Deo, S.V., Ramtekkar, G.D., 2018. For Parametric Study of Sustainable Concrete Produced using Marginal Material as an Internal Curing Agent for Partial Replacement of Natural Sand in Subtropical Climate of Central India. International Journal of Advance Research and Development. Volume 3(1),pp. 109-119 